ceptives, usually condoms and spermicides, are provided with these free of charge. If we could avoid the need to use two forms of contraception at the same time this would result in a considerable saving of money to the NHS, but above all it would relieve couples from the nuisance and inconvenience of having to use mechanical contraceptives, which so many of them dislike.

NANCY LOUDON

Lothian Health Board, Family Planning Services, Edinburgh

\section{Geriatrics in isolation}

SIR,-It is difficult to share Dr W B Wright's view (30 July, p 315) that the confinement of doctors exclusively to an older group of patients would not provide the incentive for recruitment. Clearly there is no lack of incentive for recruitment of doctors to provide care exclusively to children (paediatrics). Some regions have already tried to make combined appointments, with some sessions in general medicine and most sessions devoted to geriatric medicine; this does not seem to have improved the situation significantly. It does not appear that Dr W E Bagnall and his colleagues (9 July, $p$ 102) were advocating that the department of geriatric medicine should work "in isolation." It seems that they are able to provide a comprehensive service which is not in isolation. This can be done with the facilities, including the siting of most geriatric beds in three general hospitals where all the work in "acute" specialties are carried out, and adequate staffing, including 13 full-time doctors for 433 beds, which are available to them. In addition they seem to have good understanding and close co-operation from other clinical colleagues and administrators working in the same hospitals. There are also other units up and down the country which are providing efficient geriatric services and which have very similar facilities and staffing. With the redistribution of existing resources in the district, as recommended in the consultative document in $1976,{ }^{1}$ the difficulties in recruitment could be overcome and consequently it should be possible to provide an efficient geriatric service in all districts.

Many clinicians view geriatric medicine as an "unattractive" specialty mainly because of lack of knowledge of the "content" of geriatric medicine and very often junior doctors are dissuaded from taking up geriatrics by their seniors. On the other hand most geriatricians find the job to be busy, interesting, challenging, and rewarding. The other main factors causing difficulties in recruitment are lack of beds in general hospitals and the fact that in some districts there are still 200 or more beds allocated to one consultant geriatrician, while the level of junior medical staff available to him may be unacceptably low. In 1948 there were four consultant geriatricians and by 1973 more than 300.2 In 1975 about $10 \%$ of geriatric consultant posts in England and Wales were unfilled, but this partly reflects expansion of the specialty. Although recruitment has improved within the past few years, speedy expansion itself has contributed to a significant number of unfilled posts. In comparison with 25-30 years ago much has already been achieved and the system of geriatric care which has been developed in Great Britain is acknowledged as among the best in the world. The number of people over 75 is expected to rise by half a million over 10 years. It is obvious that the care of the elderly and recruitment to the specialty have to be improved. It will be unfortunate if we have to throw away what has been achieved within the last quarter of a century.
Elderly people have a special need. This can be met satisfactorily by the medical and paramedical staff who have developed expertise by working in departments of geriatric medicine over many years. This cannot be abandoned simply because some would like to think of this as being an "unattractive" specialty despite the fact that the number of doctors, juniors and seniors, working in this specialty has increased considerably over the past few years.

\section{St Luke's Hospital,}

N K Chakravorty

Huddersfield

Department of Health and Social Security, Priorities for Health and Personal Social Services in England. London, HMSO, 1976

Working Party of the Royal College of Physicians, ancet, 1977, 1, 1092.

\section{Erythromycin in renal failure}

SIR,-I was very interested in Dr Paul Sharpstone's paper "Prescribing for patients with renal failure" (2 July, p 36), but was surprised at the omission of any mention of erythromycin. May I be permitted to supply the missing information?

There is no need to alter dosage regimens of erythromycin in any degree of impairment of renal function. ${ }^{12}$ Erythromycin is mainly excreted in the liver, ${ }^{3}$ with some enterohepatic circulation $^{4}$ and elimination in the faeces. ${ }^{5}$ Only $2-5 \%$ of orally administered erythromycin appears in the urine, or up to $15 \%$ after intravenous administration. ${ }^{16}$ Neither peritoneal dialysis nor haemodialysis makes any significant alteration in serum levels of the drug. ${ }^{1}$

M ST G WheELEY Medical Adviser,
Abbot Laboratories Ltd

Queensborough, Kent

The Pharmacological Basis of Therapeutics, ed L S York, Macmillan, 1970.

Bennett, W M, et al, fournal of the American Medical Association, 1974, 230, 1554

The Pharmacological Basis of Therapeutics, ed L S Goodman and A Gilman, 5th edn, p 1108. New York, Macmillan, 1970

cology and Therapeutics, 1961,2 , 308 .

cil Proceedings 308 .

$1952,27,28$ Martindale: The Extra Pharmacopoeia, ed A Wade,
27th edn, p 1131. London, Pharmaceutical Press, 1977

\section{Prevention and health}

SIR,-Professor I M Richardson (9 July, p 128) calls for "a more clearly identifiable preventive responsibility." In many valuable contributions that he has made as a member of the Council for the Education and Training of Health Visitors he has been fully supported when he has raised the issue of renewed emphasis in the field of prevention-in this instance in relation to the development of health visiting. Recently this statutory body, which of course has responsibility for health visitor education and training, has been encouraged by the many reports in which the role of the health visitor has been acknowledged and the request made for more health visitors, a service running at the moment possibly at about half strength. At the same time the council is gravely concerned that recruitment to health visitor courses fell in the United Kingdom as a whole by $5.8 \%$ in 1976 , and preliminary returns suggest that it may fall again by upwards of $10 \%$ in 1977 .

The Government has suggested a move towards resources for the preventive and community services. ${ }^{1}$ Professor Thomas Mckeown has pointed out to doctors that their role must be to educate, inform, advise, stimulate, and direct patients towards the basic rules of good health." The CETHV for its part is ready and willing to continue to develop health visitor courses. When, how, and by whom will the shift of emphasis to the preventive service be begun?

NoRma BatLey Director, \section{Council for the Education and
Training of Health Visitors}

London NW1

Department of Health and Social Security, Prevention and Health: Everybody's Business. London, HMSO 1976.

'McKeown, T, The Role of Medicine: Dream, Mirage or Nemesis? Rock Carling lecture 1976. London, Nuffield Provincial Hospitals Trust, 1976.

\section{Maintenance digoxin after an episode of} heart failure

SIR,-Concerning the comments of Drs S J Warrington and N A J Hamer (23 July, p 265) on our paper (19 March, p 749), our subsequent letter (21 May, p 1350) re-emphasises that all 13 patients with atrial fibrillation had impaired atrioventricular conduction ("slow fibrillators") and gives the numbers of these among those who deteriorated clinically on placebo $(4 / 16)$ and those who did not (9/30). There was no significant difference in composition between the two groups in this respect ( $P=0 \cdot 26$, Fisher's exact test).

"Rapid fibrillators" were deliberately excluded from the study to avoid the confounding influence of controlling rate. ${ }^{1}$ Historically, none of the 13 fibrillators had a ventricular rate exceeding $120 / \mathrm{min}$ and on placebo in only one of these did it exceed $100 / \mathrm{min}(110 / \mathrm{min})$. It is dangerous to assume that only "slow fibrillators" are at risk of bradycardia on digoxin. Slowing of ventricular rate in atrial fibrillation is dependent on change in serum digoxin concentration, whether the untreated rate was "rapid" or "slow."' Since by definition this rate is lower in the "slow fibrillators" we recommend a lower dose for such patients, in whom the only indication for digoxin is heart failure, than that required in "rapid fibrillators" for control of ventricular rate.

Contrary to the implications of Drs Warrington and Hamer, had fewer patients with cor pulmonale presented during the study period the chest $x$-ray taken during the placebo phase might have shown frank pulmonary oedema in more cases. Similarly, the inclusion of patients with severe lung disease, whose respiratory function tests are more likely to exhibit irreversible changes, would militate against finding a significant difference in the within-patient comparison of spirometric values on digoxin and placebo. They state that the spirometric values were especially low in those who deteriorated clinically on placebo, but in fact there was no significant difference between the measurements on digoxin in this group and those who did not deteriorate clinically $\left(\mathrm{FEV}_{1}, \mathrm{P}>0 \cdot 1 ; \mathrm{FVC}, \mathrm{P}>0.2 ; \mathrm{FEV}_{1} /\right.$ FVC, $\mathrm{P}>0 \cdot 1$; unpaired $t$-test).

Measurements of systolic time intervals were made under standard conditions. They were recorded at $10 \mathrm{am}$, after the patient's 